\title{
ПРИЧИНЫ РАСХОЖДЕНИЯ В ДАННЫХ ВЗАИМНОЙ ТОРГОВЛИ РОССИЙСКОЙ ФЕДЕРАЦИИ И ТРЕТЬИХ СТРАН *
}

\section{(C) 2021 Толмачев М.H.}

доктор экономических наук, руководитель Департамента бизнес-аналитик Финансовый университет при Правительстве Российской Федерации, Россия, Москва

E-mail: mntolmachev@fa.ru

\section{(C) 2021 Петров А. М.}

доктор экономических наук, профессор Департамента бизнес-аналитики Финансовый университет при Правительстве Российской Федерации, Россия, Москва E-mail:palmi@inbox.ru

\section{(C) 2021 Бурцева К.Ю.}

кандидат экономических наук, доцент Департамента бизнес-аналитики Финансовый университет при Правительстве Российской Федерации, Россия, Москва E-mail: aksentiya@mail.ru

В статье изучен проблемный вопрос расхождения в статистике взаимной торговли партнерских стран. Определены несоответствия данных о торгово-экономических отношениях Российской Федерации и ее ключевых торговых партнеров. Сравнение российских показателей со статистикой различных стран мира необходимо для того, чтобы снизить влияние всевозможных факторов в долгосрочной перспективе. С этой целью предложены стратегии по снижению расхождений в статистических сведениях.

Ключевые слова: Россия, внешнеэкономическая деятельность, статистика, расхождение статистики, причины расхождения статистики, сотрудничество, торговое сотрудничество.

Существуют различные базы статистических данных по показателям внешнеэкономической деятельности многих стран мира, поддерживаемые и составляемые международными организациями. Данные организации собирают и анализируют сведения национальных статистических учреждений и агентств. Для регулярного сопоставления сведений о внешней торговле России с ее ключевыми партнерами можно использовать базы данных: Федеральной таможенной службы (ФТС), МВФ, Евростат, Межгосударственного статистического комитета СНГ, а также Организации Объединенных Наций. Исследование всех вышеперечисленных источников свидетельствует о наличии как системных, так и внесистемных расхождений [2].

Проблема расхождения во внешнеэкономических показателях торговли заключается в разнице данных по экспорту одной страны и им- порту ее партнера (на практике такая разница может иметь значительную доли всего объема внешнеторговых операций). Данное исследование посвящено изучению проблемного вопроса установления причин расхождения в данных взаимной торговли Российской Федерации и третьих стран.

Согласно решению Коллегии Евразийской экономической комиссии от 25 декабря 2018 г. № 210 «Об утверждении Методологии ведения статистики взаимной торговли товарами государств-членов Евразийского экономического союза и Методологии ведения таможенной статистики внешней торговли товарами государств-членов Евразийского экономического союза» расхождение статистических данных государства-члена и третьей страны о торговле товарами между ними может быть вызвано причинами, представленными на рисунке 1.

\footnotetext{
* Статья подготовлена по результатам исследований, выполненных за счет средств по государственному заданию Финуниверситета
} 


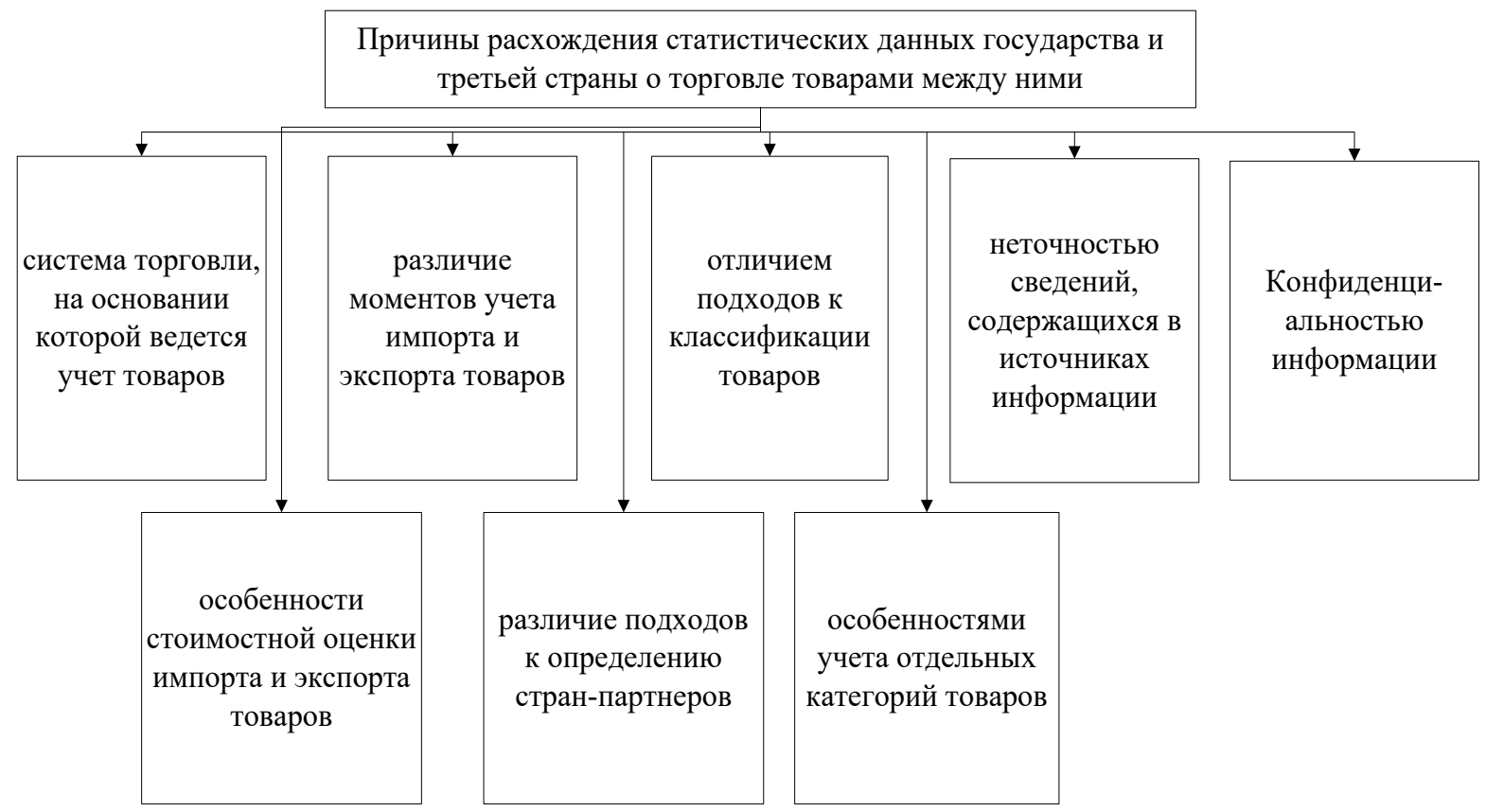

Рисунок 1. Причины расхождения статистических данных государства и третьей страны о торговле товарами между ними Источник: составлено автором по материалам [8]

На рисунке 2 более детально представлены возможные объяснения случаев, когда заявленный экспорт превышает заявленный импорт и когда заявленный экспорт ниже заявленного импорта.

Согласно информации с сайта Федеральной Таможенной Службы основными партнерами по внешней торговле с Российской Федерацией являются Германия, Италия, Нидерланды, Польша, Финляндия, Франция, Китай, Республика Корея, США и Япония.

Рассмотрим Нидерланды, по данным Таможенной службы цена экспорта товаров в эту страны составил 44789,0 миллионов долларов. По данным Trading Statistics импорт из России в Нидерланды составил 35934.00 миллионов евро или (с учетом курса) 43120.00 миллионов долларов. Расхождение составило 1669 миллионов долларов. В чем же может быть причина? Дело в том, что российские товары перегружаются в порту Роттердам и далее транзитом через Нидерланды направляются в другие страны. Их конечный пункт назначения можно определить при сопоставлении показателей внешней торговли России с аналогичными данными этих стран [4].

Или другой пример, связанный уже с импортом товаров. Китай поставляет в Россию меньше техники, чем отражено в российских данных об импорте китайской электроники. Это связано с тем, что по международным стандартам импорт учитывается по стране происхождения товара. Даже если гаджеты китайского производства были привезены, например, из Финляндии, в российском товарообороте это все равно будет учтено как торговля с Китаем [4].

Специалисты ФТС установили типичные причины расхождений в данных взаимной торговли и привели отдельные примеры (рисунок 3).

Основные причины расхождения статистики достаточно изучены и исследованы, хотя степень влияния каждого фактора в рамках определенного периода времени различна. Все вышеперечисленные факторы можно назвать объективными факторами, которые приводят к расхождению статистических данных. Сравнение российских данных с данными по остальным странам мира необходимо для того, чтобы снизить влияние различных факторов в долгосрочной перспективе. 


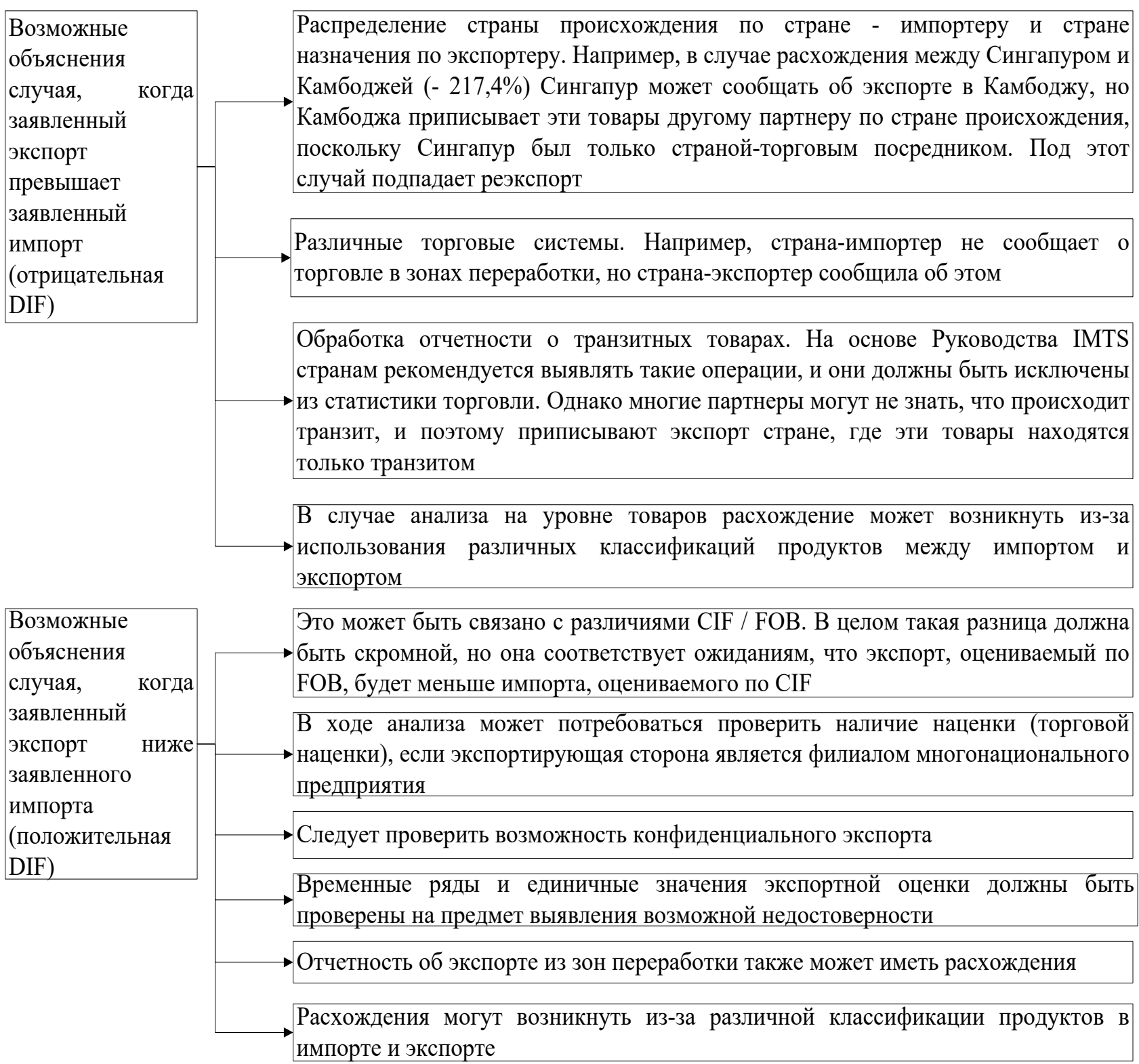

Рисунок 2. Объяснения случаев, когда заявленный экспорт превышает заявленный импорт и когда заявленный экспорт ниже заявленного импорта Источник: составлено автором по материалам [9] 
Разные методологические подходы к Пример: Россия -ЕС

ведению статистики внешней Товары, ввезенные в страны ЕС и помещенные под режим торговли у России и ее торговых свободного склада, учитываются там в статистике внешней партнеров. В соответствии с- торговли только после их выпуска в свободное обращение (на рекомендациями ООН в России складе товары могут храниться несколько лет), тогда как в экспорте -используется «общая» система учета России - по дате выпуска товара (принятие таможенным органом торговли, тогда как, например, в решения о выпуске и фактический вывоз товаров с территории

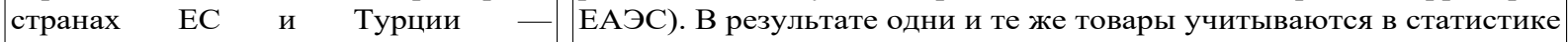
«специальная» в разное время

Разные подходы к классификации товаров, перемещаемых в рамках взаимной торговли. В разных странах один и тот же товар может классифицироваться различными кодами ТН ВЭД (товарная номенклатура внешнеэкономической деятельности)

Включение данных, относящихся к одной и той же сделке, в различные периоды (так называемые переходящие поставки)

\section{Пример: Россия - Корея}

Корейские машинокомплекты, поставляемые для сборки на заводы в Россию, классифицируются корейцами как готовые автомобили, а в России - как набор компонентов (двигатели, кузовы, шасси), каждый из которых имеет свой код. В первом полугодии 2018 года импорт корейских легковых автомобилей в Россию (код 8703) был ниже экспорта Кореи в Россию, а по запчастям для автомобилей импорт России превысил экспорт Кореи

\section{Пример: Россия - СШША}

Это особенно актуально для торговли удаленных друг от друга стран. Время доставки из России в США и наоборот может сильно варьироваться в зависимости от используемого транспорта или характеристик перевозимого товара. Товары, оформленные на экспорт в конце 2018 года с учетом времени транспортировки, будут учтены в импорте страны-партнера в начале 2019 года

\section{Реэкспорт товаров Пример: Россия - Финляндия}

производства третьих стран. Практически все В импорте принимающей страны (в соответствии с международной методологией страны включают в свой экспорт товары несобственного происхождения учета товаров, рекомендованной $\mathrm{OOH}$ ) эти товары учитываются по стране $\rightarrow$ происхождения. Этот фактор сильно влияет на расхождения данных таможенной статистики России и стран ЕСВ частности, в 2018 году импорт России из Финляндии был ниже экспорта Финляндии в Россию. Это связано с тем, что около $61 \%$ ввезенных из Финляндии в Россию товаров произведено в других странах ЕС, Китае, США или Японии. Частично они были включены в экспорт Финляндии в Россию, а в импорте России учитывались по стране происхождения

\section{Поставки}

российских товаров и товаров, произведенных страной торговым партнером, территорий третьих стран

Осуществление экспертных досчетов

Это особенно характерно для поставок в Россию товаров китайского происхождения с других территорий (ЕС, Гонконг, Республика Корея). В российском импорте они $\rightarrow$ учитываются по стране происхождения (Китай), но в данных Китая об экспорте в Россию не отражаются. Этим обусловлено превышение данных России, в частности, по товарам 84-й группы товарной номенклатуры (реакторы ядерные, котлы, оборудование и механические устройства) и 85-й группы (электрические машины и оборудование, их части)

\section{Пример: Россия - ЕАЭС}

Импорт России из Киргизии в 2018 году был ниже экспорта Киргизии в Россию на $\$ 65,8$ млн. Разночтения вызваны проведением киргизской стороной досчетов на ввоз и вывоз товаров физическими лицами на основе выборочного обследования $\rightarrow$ пограничных пунктов пропуска. Результаты досчетов добавляются к объему экспорта и импорта Киргизии с государствами — членами ЕАЭС. В Республике Беларусь также осуществляются досчеты, в частности по овощам, а в Армении для формирования данных взаимной торговли используется дополнительный источник информации - транзитные декларации о перемещении товаров между Россией и

Отнесение сведений

некоторых товарных позициях конфиденциальной информации

о Арменией через территорию Грузии

\section{Пример: Россия - Финляндия}

к $\rightarrow$ В России данные о таких товарах включены в общие итоги торговли, а ряд стран, например Финляндия, закрывают информацию о некоторых товарах по просьбам участников ВЭД, что влияет на расхождения в данных

Рисунок 3. Типичные причины расхождений в данных взаимной торговли Источник: составлено автором по материалам [4] 
Предложим стратегии по избежанию расхождений в данных:

- Сосредоточение на согласовании торговых данных с основными партнерами или для целевых продуктов.

- Принятие и применение шаблонов, согласованных странами-партнерами, а, при необходимости, их корректировка с учетом национальных условий.

- Сбор дополнительных элементов данных, которые обычно не собираются для статистики торговли, но имеют решающее значение для анализа и уменьшения двусторонней асимметрии.

- Совершенствование методов оценки и использование дополнительных источников данных, например выборочных обследований.

- Осуществление более тесного межве- домственного сотрудничества (включая Таможенную администрацию, Центральный банк, Национальное статистическое управление) и торговые ассоциации в устранении расхождений или повышении качества данных.

- Отслеживание существенных необъяснимых расхождений в каждом конкретном случае с соответствующими учреждениями.

Понимание относительных значений и динамики показателя расхождения относительно общего экспорта страны - реэкспортера помогают сделать вывод о тенденции, обобщить факторы, а также выделить те из них, которые, подходя по специфику страны, порождают несоответствия. Принятие стратегии по избежанию расхождений в данных может положительно отразится на снижении двусторонней асимметрии.

\section{Библиографический список}

1. База данных Организации Объединенных Наций - Электрон. дан.- Режим доступа: https://comtrade. un.org/data/ (дата обращения 30.05.2021).

2. Бурцева К.Ю. Анализ расхождений статистических данных по внешнеэкономической деятельности российской федерацией и ее ключевых торговых партнеров / Экономические науки - М: 2021. - № 7(200).

3. Бурцева К.Ю. Анализ преимуществ интеграции для Ирана и ЕАЭС/ Экономические науки - М: 2020.№ 7(188). - C. 109-113.

4. Константинов А. Коварная статистика: откуда расхождения в данных о внешней торговле - Электрон. дан.- Режим доступа: https://www.rbc.ru/opinions/economics/18/06/2019/5d07b0479a794756ffabd7a4. (дата обращения 30.05.2021).

5. Министерство экономического развития - Электрон. дан.- Режим доступа: http://www.ved.gov.ru/ monitoring/foreign_trade_statistics/countries_breakdown/ (дата обращения 30.05.2021).

6. Статистика внешней торговли. По данным ФТС России - Электрон. дан.- Режим доступа: https://ru-stat. com/date-Y2016-2020/RU/export/CN (дата обращения 30.05.2021).

7. Федеральная служба государственной статистики - Электрон. дан. - Режим доступа: https://rosstat.gov.ru/ folder/11193 (дата обращения 30.05.2021).

8. Федеральная таможенная служба - Электрон. дан.- Режим доступа: https://customs.gov.ru/folder/767 (дата обращения 30.05.2021).

9. Asymmetries in international merchandise trade statistics a case study of selected countries in Asia pacific Электрон. дан.- Режим доступа: http://docplayer.net/30058356-Asymmetries-in-international-merchandisetrade-statistics-a-case-study-of-selected-countries-in-asia-pacific.html (дата обращения 30.05.2021). 